\title{
A STUDY OF THE UROLOGICAL COMPLICATIONS FOLLOWING SEX REASSIGNMENT SURGERY
}

\author{
Aysha Shaheen Basheer1, Vetrichander Sattanathan²
}

${ }_{1}^{1}$ Associate Professor, Department of Urology, Tamilnadu Dr. MGR University, Chennai, Tamilnadu, India.

${ }^{2}$ Assistant Professor, Department of Urology, Tamilnadu Dr. MGR University, Chennai, Tamilnadu, India.

\section{BACKGROUND}

ABSTRACT

Sex reassignment surgery is the GOLD standard in the management of gender dysphoria. As the issue of gender dysphoria is on the rise, new management strategies need to be evolved in the way of multidisciplinary approach. Contrary to other countries, India lacks a definite policy and legislation towards transsexuals. Lack of insurance coverage for SRS and paucity of specialised tertiary centres compel the gender dysphoric to seek medical assistance from persons who lack formal training and also resort to traditional methods with high morbidity, seriously undermining their quality of life and hampering future reconstructive procedures. The social stigma coupled with illiteracy and unemployment deter the transsexuals from a regular follow-up. The high rate to alcoholism and substance abuse, lack of a decent job and low self-esteem make them vulnerable to unsafe sex practices and acquiring HIV and other STD. Paucity of the Indian inputs in medical literature concerning transsexualism was noted by the authors. They also found deficiencies in the Indian Law as applied to the individuals undergoing gender affirmation surgery (GAS).(1) Transsexuals experience themselves as being of the opposite sex, despite having the biological characteristics of one sex. [2] Aim- To study the urological complications following Sex Reassignment Surgery in male to female individuals in a tertiary institute for a period of 1 year.

\section{MATERIALS AND METHODS}

All post SRS patients who attended the Urology OP between January 2012 and December 2012 in a tertiary institute were included in the study. A total of 33 patients were studied, clinically evaluated and subjected to USG, Uroflowmetry, Urine culture, Renal function test and CT scan in selected cases. The observations were recorded and statistically evaluated. There was obstructive voiding disorder due to progressive meatal stenosis.

\section{RESULT}

In our study, urologist was not involved in any of the surgeries. Most of the complications were preventable. Severe complications were seen in surgeries done by inadequately trained persons. Lack of proper follow-up aggravates the situation. It must be mandatory for the urologist to be included in primary surgery. A proper mucosal to mucosal apposition is needed to prevent urethral stenosis. Patient must be motivated to come for regular follow-up.

\section{CONCLUSION}

GID is a complex disorder and a clinical entity demanding a multidisciplinary approach. The goal is to produce an outward appearance consistent with the patient's gender identity. Hormonal and surgical treatment should be managed by a multiprofessional team familiar with the procedures.[3] In my study, urologist was not involved in any of the surgeries. Most of the complications were preventable. Severe complications were seen in those surgeries done by inadequately trained persons. Lack of proper follow-up aggravates the situation. It must be mandatory for the urologist to be included in primary surgery. A proper mucosal to mucosal apposition is needed to prevent urethral stenosis. Patient must be motivated to come for regular follow-up. Male-to-female surgery can achieve excellent cosmetic and functional results. Although, the operative technique is partly standardised, surgery remains challenging because of several possible complications. None of the present patients claimed to regret their decision to undergo gender-transforming surgery.[4]

\section{KEY WORDS}

GID- Gender Identity Disorder, GAS- Gender Affirmation Surgery, SRS- Sex Reassignment Surgery, FTM- Female-to-Male, MTFMale-to-Female, PVR- Post-Void Residue, USG- Ultrasonogram, CT- Computed Tomogram, AUG- Ascending Urethrogram, SPCSuprapubic Catheter, PN- Pyelonephritis.

HOW TO CITE THIS ARTICLE: Basheer AS, Sattanathan V. A study of the urological complications following sex reassignment surgery. J. Evolution Med. Dent. Sci. 2018;7(42):4487-4492, DOI: 10.14260/jemds/2018/1001

'Financial or Other Competing Interest': None.

Submission 08-09-2018, Peer Review 01-10-2018,

Acceptance 04-10-2018, Published 15-10-2018.

Corresponding Author:

Dr. Vetrichander Sattanathan,

Assistant Professor,

1G6, DABC Mithilam Plots,

Sriram Nagar, Nolambur, Chennai-95,

Tamilnadu, India.

E-mail:drsvchandar@gmail.com

DOI: $10.14260 /$ jemds/2018/1001

\section{BACKGROUND}

Urological Complications following URS

Lower Urinary Tract Symptoms

1. Obstructive voiding disorder due to progressive meatal stenosis.

2. Urinary retention mostly observed 3 to 4 months after the second surgery (4\%).

3. Dribbling (8\%).

4. Stress urinary incontinence, grades I - II.

5. Urgency and urge incontinence.

6. Urethral injury was found in (4\%) requiring primary repair. 
7. Distal urethral necrosis in (1\%).

8. Neomeatus bleeding occurred in (3\% requiring external haemostatic sutures of its walls or catheterisation with 22-Fr catheter.

9. Complete urethral stricture.

\section{Infective and Inflammatory Complications}

Meatal stenosis or urethral narrowing causing significant post-void residue causes recurrent cystitis and ascending infection and PN when the host immunity is compromised or when the causative organism is highly virulent. The most common pathogens are E. coli, Staphylococcus aureus and Proteus species.[5]

\section{Perinephric Abscess}

Most perinephric abscesses result from ascending infection or dissemination from other sites of infection. Percutaneous drainage under image guidance is the treatment of choice. If it fails or is contraindicated, open surgical drainage is performed.

\section{MATERIALS AND METHODS}

\section{Study Group}

All transgenders who attended the Urology OP between January 2012 and December 2012.

\section{Study Design}

Observational study.

\section{Materials}

- $\quad$ Patient evaluation, history.
- Place of surgery, date of surgery and the qualification of the primary surgeon are noted down.

- History of hypertension, diabetes and HIV status recorded.

- General examination: Fever, pallor and lymphadenopathy are noted.

- Abdomen palpated for bladder distension.

\section{Investigations}

Urine routine exam, Urine culture and sensitivity, Blood urea sugar creatinine, HIV status, Haemogram, AUG, Uroflowmetry, USG, Cystoscopy, X-ray Chest, X-ray KUB, CT Scan abdomen. In patients presenting with acute urinary retention, SPC was done.

\section{Post-Operative Period}

Catheter removed either on 7 or 10 days as dictated by the nature of surgery.

In Meatoplasty, catheter was retained for a week and in urethroplasty for 10 days.

At the end of 14 days, PVR was assessed by USG and Uroflowmetry was done.

\section{Statistical Analysis}

The data obtained were subjected to following statistical tests. Chi-square test to compare proportions, to compare means and percentages. Data were analysed with the SPSS 20 software and a p-value of 0.05 or less was considered statistically significant.

\section{RESULTS}

\section{Based on Symptomatology}

Sex reassignment surgery was done by traditional group of people and general surgeons and plastic surgeons based on their symptoms were followed up and tabulated as follows:

\begin{tabular}{|c|c|c|c|c|c|c|c|c|c|}
\hline & \multicolumn{5}{|c|}{ Symptom } & \multirow[b]{2}{*}{ Total } & \multirow[b]{2}{*}{$\begin{array}{c}\text { P-value } \\
\text { (Chi-Square } \\
\text { Test) }\end{array}$} \\
\hline & & & LUTS & $\begin{array}{c}\text { LUTS+ Fistula } \\
+ \text { AUR + Sepsis }\end{array}$ & $\begin{array}{l}\text { LUTS + } \\
\text { Fistula }\end{array}$ & LUTS + AUR & $\begin{array}{l}\text { LUTS + } \\
\text { Sepsis }\end{array}$ & & \\
\hline \multirow{9}{*}{ 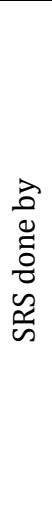 } & \multirow{3}{*}{ Traditional } & Count & 2 & 9 & 1 & 7 & 1 & 20 & \multirow{12}{*}{0.001} \\
\hline & & $\begin{array}{c}\% \text { within SRS done } \\
\text { by }\end{array}$ & $10.0 \%$ & $45.0 \%$ & $5.0 \%$ & $35.0 \%$ & $5.0 \%$ & $100.0 \%$ & \\
\hline & & $\%$ within symptom & $40.0 \%$ & $56.3 \%$ & $14.3 \%$ & $100.0 \%$ & $100.0 \%$ & $55.6 \%$ & \\
\hline & \multirow{3}{*}{$\begin{array}{l}\text { General } \\
\text { Surgeon }\end{array}$} & Count & 0 & 7 & 6 & 0 & 0 & 13 & \\
\hline & & \begin{tabular}{|c|}
$\begin{array}{c}\% \text { within SRS done } \\
\text { by }\end{array}$ \\
\end{tabular} & $0.0 \%$ & $53.8 \%$ & $46.2 \%$ & $0.0 \%$ & $0.0 \%$ & $100.0 \%$ & \\
\hline & & $\%$ within symptom & $0.0 \%$ & $43.8 \%$ & $85.7 \%$ & $0.0 \%$ & $0.0 \%$ & $36.1 \%$ & \\
\hline & \multirow{3}{*}{$\begin{array}{l}\text { Plastic } \\
\text { Surgeon }\end{array}$} & Count & 3 & 0 & 0 & 0 & 0 & 3 & \\
\hline & & $\begin{array}{c}\text { \% within SRS done } \\
\text { by }\end{array}$ & $100.0 \%$ & $0.0 \%$ & $0.0 \%$ & $0.0 \%$ & $0.0 \%$ & $100.0 \%$ & \\
\hline & & $\%$ within symptom & $60.0 \%$ & $0.0 \%$ & $0.0 \%$ & $0.0 \%$ & $0.0 \%$ & $8.3 \%$ & \\
\hline & \multirow{3}{*}{ Total } & Count & 5 & 16 & 7 & 7 & 1 & 36 & \\
\hline & & $\begin{array}{c}\% \text { within SRS done } \\
\text { by }\end{array}$ & $13.9 \%$ & $44.4 \%$ & $19.4 \%$ & $19.4 \%$ & $2.8 \%$ & $100.0 \%$ & \\
\hline & & $\%$ within symptom & $100.0 \%$ & $100.0 \%$ & $100.0 \%$ & $100.0 \%$ & $100.0 \%$ & $100.0 \%$ & \\
\hline
\end{tabular}

\section{Sex Reassignment Surgery based on Intervention with Suprapubic Catheterisation}

Sex reassignment surgery done by traditional methods and general surgeon and plastic surgeons based on intervention by Suprapubic Catheterisation (SPC) were tabulated as follows: 


\begin{tabular}{|c|c|c|c|c|c|c|}
\hline & \multicolumn{2}{|c|}{ SPC } & \multirow[t]{2}{*}{ Total } & \multirow{2}{*}{$\begin{array}{c}\text { P-value } \\
\text { (Chi-Square Test) }\end{array}$} \\
\hline & & & Yes & No & & \\
\hline \multirow{9}{*}{$\begin{array}{l}\hat{a} \\
0 \\
\tilde{0} \\
0 \\
\tilde{D} \\
\tilde{s}\end{array}$} & \multirow{3}{*}{ Traditional } & Count & 16 & 4 & 20 & \multirow{12}{*}{0.006} \\
\hline & & \% within SRS done by & $80.0 \%$ & $20.0 \%$ & $100.0 \%$ & \\
\hline & & \% within SPC & $76.2 \%$ & $26.7 \%$ & $55.6 \%$ & \\
\hline & \multirow{3}{*}{ General Surgeon } & Count & 5 & 8 & 13 & \\
\hline & & \% within SRS done by & $38.5 \%$ & $61.5 \%$ & $100.0 \%$ & \\
\hline & & \% within SPC & $23.8 \%$ & $53.3 \%$ & $36.1 \%$ & \\
\hline & \multirow{3}{*}{ Plastic Surgeon } & Count & 0 & 3 & 3 & \\
\hline & & \% within SRS done by & $0.0 \%$ & $100.0 \%$ & $100.0 \%$ & \\
\hline & & \% within SPC & $0.0 \%$ & $20.0 \%$ & $8.3 \%$ & \\
\hline & \multirow{3}{*}{ Total } & Count & 21 & 15 & 36 & \\
\hline & & $\%$ within SRS done by & $58.3 \%$ & $41.7 \%$ & $100.0 \%$ & \\
\hline & & \% within SPC & $100.0 \%$ & $100.0 \%$ & $100.0 \%$ & \\
\hline
\end{tabular}

Surgical procedures done for complications in sex reassignment surgery patients in their serial follow-up were studied based on intervention by traditional group, general surgeons and plastic surgeons and tabulated as follows:

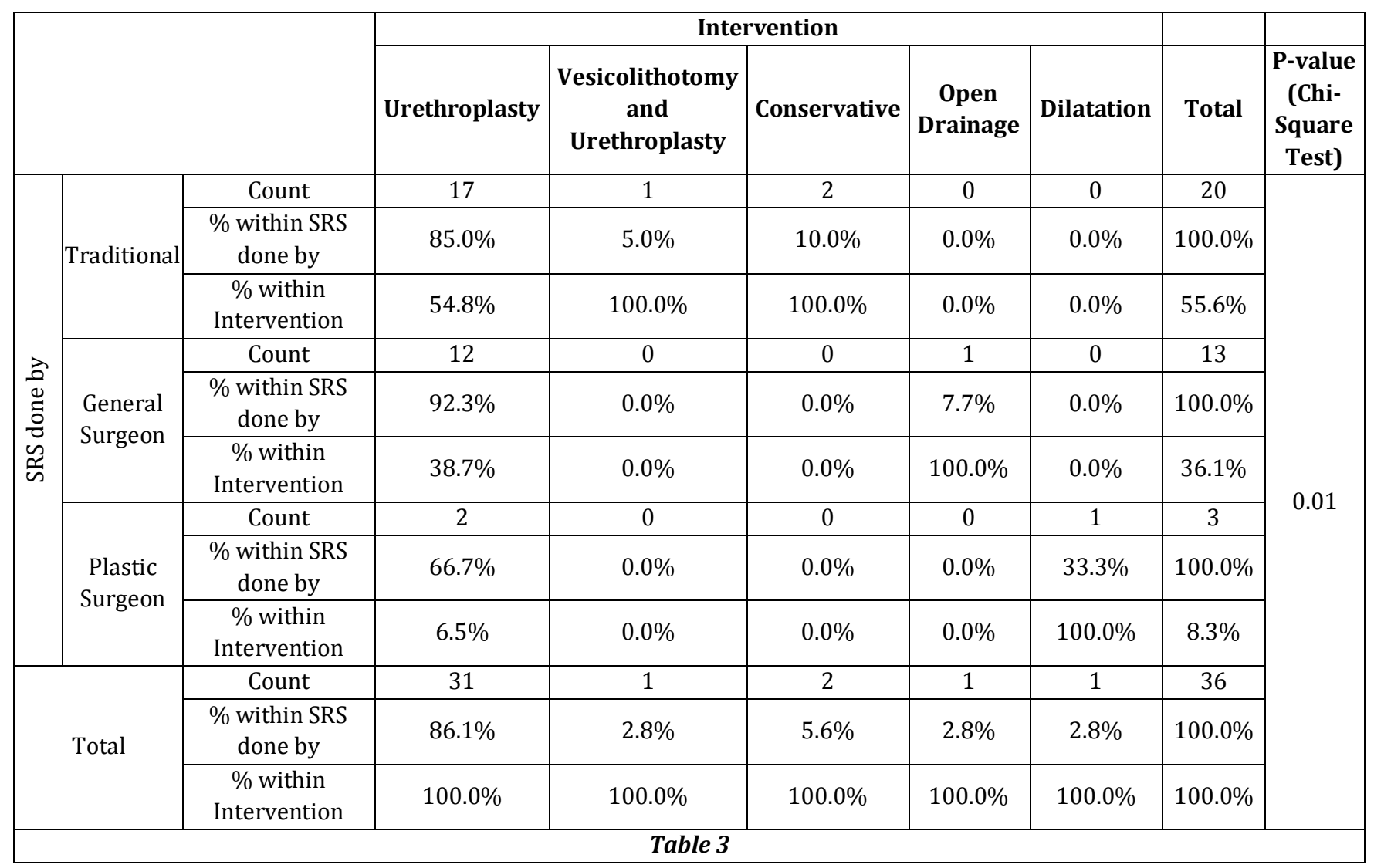

Extent of urethral scarring was studied in the follow-up of sex reassignment surgery patients. The length, density and location of the scar in all patients were studied and the extent of scarring was compared with traditional group, general surgeon and plastic surgeons were tabulated as follows.

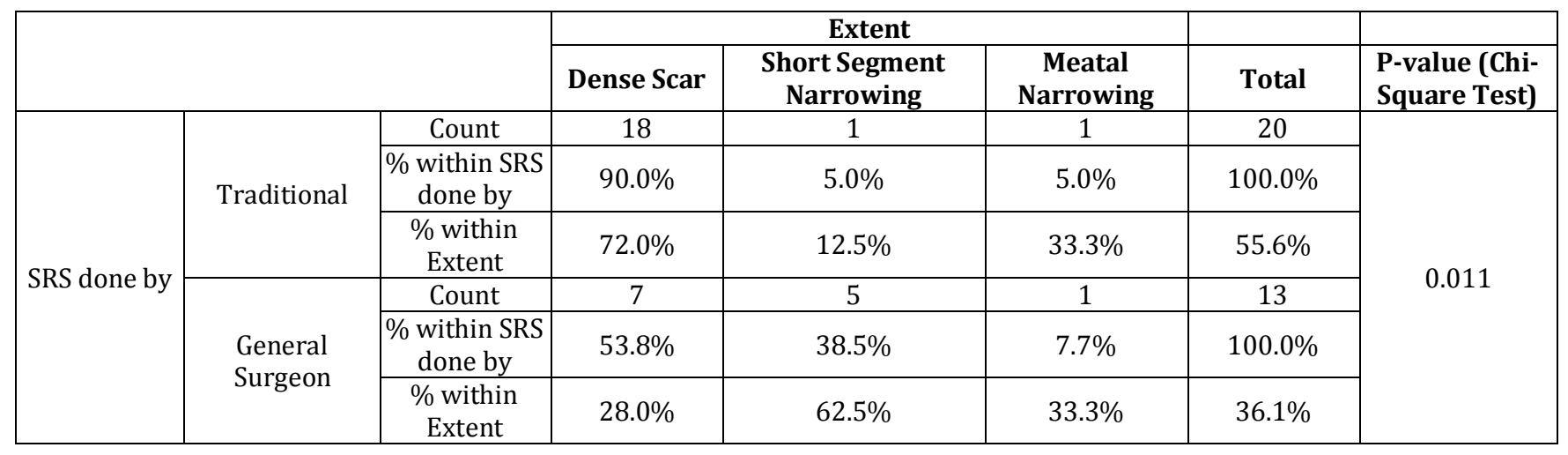




\begin{tabular}{|c|c|c|c|c|c|}
\hline \multirow{3}{*}{ Plastic Surgeon } & Count & 0 & 2 & 1 & 3 \\
\hline & $\begin{array}{c}\% \text { within SRS } \\
\text { done by }\end{array}$ & $0.0 \%$ & $66.7 \%$ & $33.3 \%$ & $100.0 \%$ \\
\hline & $\begin{array}{c}\text { \% within } \\
\text { Extent }\end{array}$ & $0.0 \%$ & $25.0 \%$ & $33.3 \%$ & $8.3 \%$ \\
\hline \multirow{3}{*}{ Total } & Count & 25 & 8 & 3 & 36 \\
\hline & $\begin{array}{c}\% \text { within SRS } \\
\text { done by }\end{array}$ & $69.4 \%$ & $22.2 \%$ & $8.3 \%$ & $100.0 \%$ \\
\hline & $\begin{array}{c}\text { \% within } \\
\text { Extent }\end{array}$ & $100.0 \%$ & $100.0 \%$ & $100.0 \%$ & $100.0 \%$ \\
\hline
\end{tabular}

\section{DISCUSSION}

To understand transsexuality, we have to understand the difference between sex and gender. While 'sex' represents physical differentiation as male or female, indicated by the external appearance of genitalia and the presence of gonads, 'gender' is the psychological recognition of self and wish to be regarded by others as fitting into the social categories such as boy/ man or girl/ woman. In short, sex is what one is seen as (external appearance as male/ female) and gender being the identity is what one feels (playing the role of and living the life of male/ female).[6]

Harry Benjamin (1885 - 1986) ${ }^{[3]}$ recognised transsexualism, treated hundreds of patients and established the modern scientific management of this condition. He wrote many books, especially 'The Transsexual Phenomenon' in 1966.[7]

The morphological proportions of each patient vary and the different shapes and sizes of the tissues can be used for plastic operations. Thus, the modelling of each individual genital in transsexuals can be considered 'original.' [3]

In my study all 36 patients were transwomen. All except one were school dropouts coming from a low social stratum. Most of them were isolated from their original families once they started developing symptoms of gender dysphoria and started living with their peer groups. Most of them earned their livelihood through begging or performing folk dances. Only one of the patients took oestrogen and progesterone therapy for breast development.

Two of the 36 people were engaged as commercial sex workers. Two of them were married to seemingly normal men.

All of them were garishly dressed as females with female mannerisms and all were mostly polite but demanded immediate attention. ${ }^{[8]}$

Oestrogen alone therapy (ET) or Oestrogen and Progestin (EPT) as menopausal Hormone Therapy (HT) has been commonly used to alleviate menopausal symptoms. Treatments containing $\geq 10$ days/ month $(d / m)$ of progestin are considered relatively safe with respect to endometrial cancer risk. However, the endometrial safety of long-term EPT regimens is uncertain. ${ }^{[9]}$

\section{Age Group}

Youngest member was 19 years and oldest was 50 years. The mean age was 27 years.

\section{Primary Surgery \\ Primary Surgery was one by either of the 3 Group of Persons-}

1. Traditional group comprised of quacks and transsexuals.
2. Surgery done by general surgeons.

3. Surgery done by plastic surgeons.

- In my study, 20 individuals have undergone SRS by traditional methods accounting for $55 \%$.

- 13 persons had undergone surgery by general surgeon accounting for $36 \%$.

- Only 3 of them underwent surgery by plastic surgeon accounting for $8.3 \%$.

\section{Symptomatology}

$30 \%$ of the patients presented to OPD within 3 months of primary surgery and the rest within the next 1 year.

Majority of the patients, about 16 cases (44\%) presented with LUTS, AUR and Fistula.

5 cases $(19.45 \%)$ presented with LUTS and fistula.

Cases with Acute Urinary Retention (AUR) had a prior UTI as a precipitating cause.

Stein et al in Journal of Urology 2000 says that obstructing voiding is the commonest complication.

Patients with meatal stenosis used cloves toothpicks and ear buds to keep the meatus open.

Rehman in archives of sexual behaviour 1999 reports similar usage of objects.

Two patients presented with loin pain and tenderness and fever. One patient presented with fever with chills, acute urinary retention suggestive of frank septicaemia. There was a palpable tender mass occupying the right hypochondrium and lumbar regions and the right loin. Prior to considering surgical reassignment, the key issue for the surgeon is to establish beyond reasonable doubt that the gender dysphoria or transsexual feeling is genuine and that surgical reassignment will be beneficial.[10]

\section{Nature of Intervention}

Nature of intervention was decided on the degree of obstruction and urethral narrowing and the primary complaints. Although guidelines from organisations, such as the Harry Benjamin International Gender Dysphoria Association, have been helpful. Management remains complex and experience guided. We discuss the range of treatment used by transsexual people, the rationale behind these and the expectation from such treatment.[11]

Krege et al in 2000 recommend similar management.

1. Only dilatation.

2. Meatoplasty.

3. Revision urethroplasty.

4. Vesicolithotomy with urethroplasty.

5. Open drainage of perinephric abscess.

6. Conservative management of pyelonephritis. 


\section{1) Dilatation}

One patient who had a meatal narrowing had undergone SRS by plastic surgeons. Dilatation with metal sounds was done and voided well. An USG revealed a PVR of less than $15 \mathrm{~mL}$ and post dilatation uroflow revealed a Qmax of $22 \mathrm{~mL} / \mathrm{sec}$ compared to $12 \mathrm{~mL} / \mathrm{sec}$ before the procedure.

She was one of the 6 patients who came for follow-up for the next 3 months. She underwent dilatation on her monthly visits.

\section{2) Meatoplasty}

Meatoplasty was done for 2 patients who had undergone SRS by plastic surgeons, scarring extends just beyond the meatus. An inverted U-shaped Blandy's Flap created with perfect mucosal approximations without any major complications. After removal of catheter on 7 th postoperative day, patients voided well with Qmax of 20 $\mathrm{mL} / \mathrm{sec}$. USG revealed an insignificant PVR less than 20 $\mathrm{mL}$.

\section{3) Revision Urethroplasty}

Dense scarring involving the whole of the bulbar urethra was seen in 31 cases. Out of this, 20 was done by traditional surgeons. An inverted U-shaped incision was made in the perineum. Urethra mobilised, and sinus tract excision done. Perineal urethrostomy completed. Finally, patients were taught self-dilatation. Feldman in transgender primary care 2006 advocates urethroplasty.

\section{4) Vesicolithotomy with Urethroplasty}

One patient had formed bladder stone due to chronic bladder outflow obstruction. SRS was done again by a senior member of the group. Cystoscopy done, stones confirmed through a transverse suprapubic incision, bladder opened, and stones removed. Suspicious area biopsied. Bladder closed with SPC. Perineal urethrostomy completed. Foleys inserted. Urethral Foleys and SPC clamped on POD 12. PVR was of $30 \mathrm{~mL}$ with uroflow of $18 \mathrm{~mL} / \mathrm{sec}$.

\section{5) Open Drainage of Perinephric Abscess}

One patient who had tested positive for HIV presented with a right perinephric abscess tracking down through right psoas muscle, bladder distension, severe urethral stenosis and septicaemia and raised renal parameters. CT confirmed the diagnosis. Open flank drainage of the perinephric abscess was done. Follow-up CT revealed resolution of collection.

6) Conservative Management of Pyelonephritis

Two patients with acute pyelonephritis showed urine growth with E. coli and treated with amikacin for 1 week. They responded well and were discharged at request, but lost for further follow-up. Journal of Acute Medicine 2000 reports stenting for acute pyelonephritis with dilated collecting system.

\section{Observation in 3 Different Groups}

The incidence of LUT, AUR, Multiple Fistulas and UTI was $56 \%$.
- Incidence of flank pain was $5 \%$ compared to $52 \%$ and $0 \%$ in the general surgeon group.

- Nil incidence of sepsis or AUR in the plastic surgeons group.

- P value of 0.001 was considered statistically significant.

\section{Incidence of SPC among the Groups}

In the traditional group SPS was done in $80 \%$ of cases, whereas it was $38.5 \%$ in the general surgery group and nil in the plastic surgeon's group.

\section{Surgical Intervention among 3 Groups}

- Traditional group accounting for $54.8 \%$ of the interventions.

- General Surgeons accounted for $38.7 \%$ and Plastic Surgeons accounted for $6.5 \%$ of cases.

- P value of $0.01 \%$ was considered statistically significant.

\section{Follow-Up}

In patients with dense scarring, catheter was removed on 10th post-operative day and the rest had their catheter removed on the 7 th post-operative day.

All the patients were in their hospital for 2 weeks. At 14th day, PVR estimation was done. At 3 months, uroflowmetry for Qmax and USG for PVR was done. Of the 3 patients, only 6 were available for follow-up. At 3 months, all 6 patients with regular dilatation were symptom free with a normal voiding pattern.

\section{Limitation}

Our study comprised of only 36 patients. It has patients who had undergone only masculinisation and not the complete genital reconstruction. It was not adequately powered.

It lacked long-term follow-up. Further studies are needed to arrive at definitive conclusions.

\section{CONCLUSION}

GID is a complex disorder and a clinical entity demanding a multidisciplinary approach. The goal is to produce an outward appearance consistent with the patient's gender identity. Hormonal and surgical treatment should be managed by a multi-professional team familiar with the procedures. In my study, urologist was not involved in any of the surgeries. Most of the complications are preventable. The severe complications were seen in those surgeries done by traditional persons. Lack of proper follow-up aggravates the situation. It must be mandatory for the urologist to be included in primary surgery. A proper mucosal to mucosal apposition is needed to prevent urethral stenosis. Patient must be motivated to come for regular follow-up.

\section{REFERENCES}

[1] Gupta R, Murarka A. Treating transsexuals in India: History, prerequisites for surgery and legal issues. Indian Journal of Plastic Surgery 2008.

[2] Kruijver FP, Zhou JN, Pool CW, et al. Male-to-female transsexuals have female neuron numbers in a limbic nucleus. J Clin Endocrinol Metab 2000;85(5):2034-41.

[3] Bowman KM, Engle B. Medicolegal aspects of transvestism. Am J Psychiatry 1957;113:583-8. 


\section{Jemds.com}

[4] Krege S, Bex A, Lummen G, et al. Male-to-female transsexualism: a technique, results and long-term follow-up in 66 patients. BJU Int 2001;88(4):396-40.

[5] Grant P, Lipscomb D, Edgell H. Emphysematous pyelonephritis in a non-diabetic post-operatie transsexual patient. (Journal Article) Acute Med 2010;9(1):30-3.

[6] Asschemen H, Diamond M, Ceglie DD, et al. Definition and synopsis of the etiology of adult gender identity disorder and transsexualism. Gender Counselor Cited Aug 24. 2008.

[7] Peveller GL. Harry Benjamin Syndrome (Internet) Gender Counselor. (Cited 2008 Sep 24). http://www.gendercounseling.org/hbs.html

[8] Casella R, Bubendorf L, Schaefer DJ, et al. Transurethral resection of the prostate in a male to female transsexual 25 years after sex-changing operation. Urol Int 2005;75(3):288-90.

\section{Original Research Article}

[9] Doherty JA, Cushing-Haugen KL, Saltzman BS, et al. Long-term use of postmenopausal estrogen and progestin hormone therapies and the risk of endometrial cancer. American Journal of Obstetrics and Gynaecology 2007;197(2):139.e1-7.

[10] Hage JJ. Medical requirement and consequences of sex reassignment surgery. Medicine, Science and the Law 1995;35(1):17-24.

[11] Moore E, Wisniewski A, Dobs A. Endocrine treatment of transsexual people: a review of treatment regimens, outcomes and adverse effects. Journal of Clinical Endocrinology and Metabolism 2003;88(8):3467-73. 